identified in these cases shows clustering with sequences of African origin, as observed for our patient (6-8). However, because only a small number of sequences of DENV3 strains from Africa are available (and not all sequences refer to the same genomic region), a comparative phylogenetic analysis of strains from Africa is limited. A recent investigation of febrile patients from Gabon showed not only circulation of DENV-3, but simultaneous circulation of 3 DENV serotypes (DENV-1, DENV-2, and DENV-3) in West Africa (10).

Molecular data for travelers are useful in areas where DENV diagnosis and surveillance are not routinely performed. The case-patient reported here highlights sustained transmission of DENV-3 genotype III strains or closely related strains during recent years. Increasing numbers of reports on local outbreaks and available phylogenetic information support ongoing DENV-3 transmission in West Africa. If one assumes a maximum incubation time of 14 days, our case-patient was most probably exposed to DENV in Togo or Burkina Faso. These 2 countries have not been considered as areas to which DENV is endemic. Our findings indicate that further systematic evaluation of the risk and disease burden of dengue in Africa is urgently needed. Dengue fever should be considered in travelers returning from Africa with acute febrile illness.

\section{Acknowledgments}

We thank Ulrike Reber for excellent technical assistance and Victor M. Corman for assistance with phylogenetic analysis.

\section{References}

1. Bhatt S, Gething PW, Brady OJ, Messina JP, Farlow AW, Moyes CL, et al. The global distribution and burden of dengue. Nature. 2013;496:504-7. http://dx.doi.org/10.1038/nature12060

2. Amarasinghe A, Kuritsk JN, Letson GW, Margolis HS. Dengue virus infection in Africa. Emerg Infect Dis. 2011;17:1349-54.

3. Johnson BW, Russell BJ, Lanciotti RS. Serotype-specific detection of dengue viruses in a fourplex real-time reverse transcriptase PCR assay. J Clin Microbiol. 2005;43:4977-83. http://dx.doi. org/10.1128/JCM.43.10.4977-4983.2005

4. Drosten C, Gottig S, Schilling S, Asper M, Panning M, Schmitz H, et al. Rapid detection and quantification of RNA of Ebola and Marburg viruses, Lassa virus, Crimean-Congo hemorrhagic fever virus, Rift Valley fever virus, dengue virus, and yellow fever virus by real-time reverse transcription-PCR. J Clin Microbiol. 2002;40:2323-30. http://dx.doi.org/10.1128/JCM.40.7.23232330.2002

5. Franco L, Di Caro A, Carletti F, Vapalahti O, Renaudat C, Zeller H, et al. Recent expansion of dengue virus serotype 3 in West Africa. Euro Surveill. 2010;15:pii: 19490.

6. Nisii C, Carletti F, Castilletti C, Bordi L, Meschi S, Selleri M, et al. A case of dengue type 3 virus infection imported from Africa to Italy, October 2009. Euro Surveill. 2010;15:pii: 19487.

7. Ninove L, Parola P, Baronti C, De Lamballerie X, Gautret P, Doudier B, et al. Dengue virus type 3 infection in traveler returning from West Africa. Emerg Infect Dis. 2009;15:1871-2. http://dx.doi. org/10.3201/eid1511.081736

8. Moi ML, Ujiie M, Takasaki T, Kurane I. Dengue virus infection in travellers returning from Benin to France, July-August, 2010. Euro Surveill. 2010;15:19674.

9. Moi ML, Takasaki T, Kotaki A, Tajima S, Lim CK, Sakamoto M, et al. Importation of dengue virus type 3 to Japan from Tanzania and Côte d'Ivoire. Emerg Infect Dis. 2010;16:1770-2. http://dx.doi. org/10.3201/eid1611.101061

10. Caron M, Grard G, Paupy C, Mombo IM, Bikie Bi Nso B, Kassa Kassa FR, et al. First evidence of simultaneous circulation of three different dengue virus serotypes in Africa. PLoS ONE. 2013;8:e78030. http://dx.doi.org/10.1371/journal.pone.0078030

Address for correspondence: Isabella Eckerle, Institute of Virology, University of Bonn Medical Centre, Sigmund-Freud-Strasse 25, 53127 Bonn, Germany; email: eckerle@virology-bonn.de

\title{
Community-Acquired Invasive GAS Disease among Native Americans, Arizona, USA, Winter 2013
}

\section{Aaron M. Harris, ${ }^{1}$ Del Yazzie, ${ }^{1}$ Ramona Antone-Nez, Gayle Dinè-Chacon, J.B. Kinlacheeny, David Foley, Seema Yasmin, Laura Adams, Eugene Livar, Andrew Terranella, Linda Yeager, Ken Komatsu, Chris Van Beneden, and Gayle Langley}

Author affiliation: Centers for Disease Control and Prevention, Atlanta, Georgia, USA (A.M. Harris, S. Yasmin, L. Adams, C. Van Beneden, G. Langley); Navajo Division of Health, Window Rock, Arizona, USA (D. Yazzie, R. Antone-Nez, G. Dinè-Chacon, J.B. Kinlacheeny, D. Foley); Arizona Department of Health Services, Phoenix, Arizona (E. Livar, K. Komatsu); and Indian Health Service, Navajo Area, Arizona (A. Terranella, L. Yeager)

DOI: http://dx.doi.org/10.3201/eid2101.141148

To the Editor: Group A streptococci (GAS) can cause severe invasive diseases, such as necrotizing fasciitis, streptococcal toxic shock syndrome, and sepsis. In $2012, \approx 11,000$ cases of invasive GAS (iGAS) disease and 1,100 associated deaths occurred in the United States $(1,2)$. The risk for iGAS infection is 10 times higher among Native Americans than among the general population (3). Other predisposing factors for iGAS infection include skin wounds and underlying diseases, such as diabetes $(1,3,4)$. Household risk factors include exposure to children with pharyngitis and crowding (4). Most iGAS infections occur sporadically within the community. Postpartum and postsurgical clusters arising from a common nosocomial source occur but are rare (5).

During the winter of 2012-13, a 3-fold increase in necrotizing fasciitis was observed at an Arizona hospital ${ }^{1}$ These authors contributed equally to this article. 
(hospital X) that predominantly treats Native Americans. Tribal leadership initiated a collaborative investigation with state and federal officials to characterize the outbreak and implement appropriate control measures.

A confirmed case of iGAS was defined as isolation of GAS from normally sterile sites (i.e., blood) or isolation of GAS from nonsterile sites (i.e., wound) in the presence of necrotizing fasciitis or streptococcal toxic shock syndrome among patients who sought care at hospital X during August $2012-$ March 2013. Hospital X serves $\approx 45,000$ persons in a rural community. Eleven confirmed iGAS cases were identified (Figure), of which $8(73 \%)$ occurred in women and $3(27 \%)$ occurred in men. The case-patients had a mean age of 63 years (range 32-92 years). All cases were community-onset illnesses; none of the case-patients had recent exposures to health care settings, and all were of $\mathrm{Na}-$ tive American ancestry. Of the 11 case-patients, 8 required critical care treatment and 3 died. Nine ( $82 \%$ ) case-patients had open wounds or skin breakdown (e.g., skin abrasion, burns), and 9 had underlying medical conditions that are known risk factors for iGAS (e.g., obesity, diabetes, chronic kidney or heart disease, alcoholism).

Five GAS isolates were available. Two of the isolates were emm type 11; antimicrobial drug-susceptibility profiles for the 2 were identical (i.e., tetracycline resistant). The 2 patients reported no close contact with each other, but they had the same home health aide. The other 3 isolates had different emm types $(1,12$, and 82$)$ and were antimicrobial drug pansensitive.

We interviewed 58 household contacts of the casepatients ( 35 adults, 23 children) regarding symptoms and risks for secondary GAS infection. Among these contacts, 2 adults reported a sore throat and 6 children reported fever (without sore throat), but no confirmed secondary GAS infections were identified. Because of the known increased risk for iGAS among Native Americans and the level of crowding (average of 2-3 persons/bedroom) and the high proportion of adult household contacts with predisposing underlying conditions $(29 \%)$ in this population, azithromycin prophylaxis was offered to household contacts who spent $\geq 24$ hours with a case-patient during the 7 days preceding the onset of illness.

With the exception of the 2 case-patients with a common health aide, we found no common epidemiologic links or common behaviors among patients that suggested a single-source outbreak. This was further supported by the finding of multiple emm types among the isolates. These are not unusual findings in community outbreaks of iGAS; clusters of iGAS cases have often been observed without a common source (6-8). Localized and transient increases in sporadic GAS infections may occur because of an influx of a new emm type into a population with low levels of community immunity to that specific emm type; an increase in the detection and reporting of iGAS without a true increase in infection; or an increase in conditions that predispose persons to iGAS, such as GAS pharyngitis among children or concurrent influenza or other virus outbreaks in the community.

Past studies have shown that the risk of secondary iGAS infection among household contacts of patients with iGAS disease is higher than that among the general population but still low (5). Although Centers for Disease Control and Prevention guidelines do not recommend routine chemoprophylaxis for household contacts of patients with iGAS infection, the guidelines state that providers may choose to offer antimicrobial drug prophylaxis

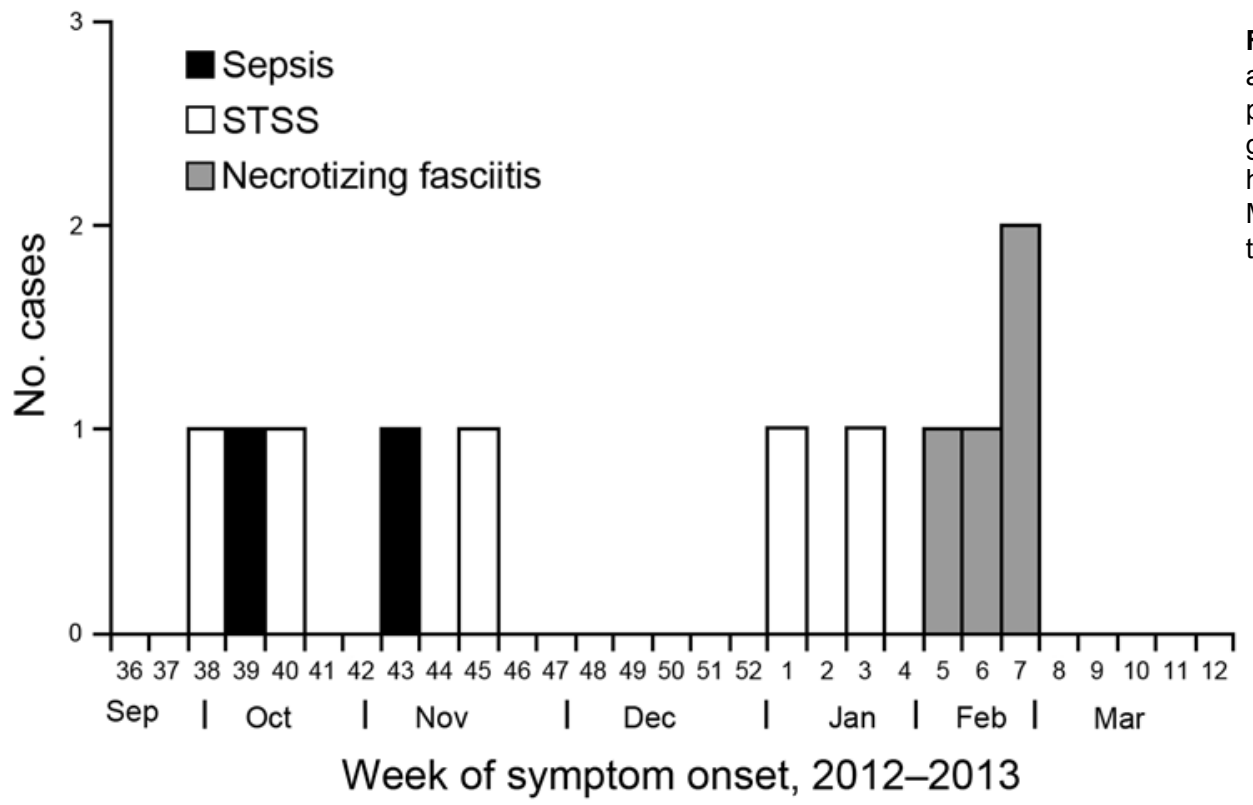

Figure. Week of symptom onset and principal clinical syndrome of patients with confirmed invasive group A streptococcus infections at hospital X, Arizona, August 2012March 2013. STSS, streptococcal toxic shock syndrome. 
to those household contacts at increased risk for iGAS infection (5). Because Native Americans have increased rates of iGAS disease, compared with those of the general population, and because households in this investigation were crowded and many contacts had predisposing underlying conditions, we recommended that household contacts receive prophylaxis if given within 30 days of the index case-patient's illness (5). No additional cases were reported at least 3 months after the investigation and intervention.

\section{Acknowledgments}

We gratefully acknowledge the contributions of the Navajo Nation Vice-President, Rex Lee Jim, and of Adella Begaye, Kathleen Atene, Jerilene Vann, Elizabeth Ellis, Karen Thomas, Stephanie Wilson, Roland Begay, Linda Ross, Sheila Goldtooth, Polly Thompson, Philene Herrera, Douglas Peter, Jenny Notah, Roselyn Begay, Simental Francisco, and Darlene Tracy.

\section{References}

1. Active Bacterial Core Surveillance (ABCs). ABCs report: group A Streptococcus, 2012. [cited 2014 May 1]. http://www.cdc.gov/abcs/ reports-findings/survreports/gas $12 . \mathrm{html}$

2. O’Brien KL, Beall B, Barrett NL, Cieslak PR, Reingold A, Farley MM, et al. Epidemiology of invasive group A

Streptococcus disease in the United States, 1995-1999. Clin Infect Dis. 2002;35:268-76. http://dx.doi.org/10.1086/341409

3. Hoge CW, Schwartz B, Talkington DF, Breiman RF, MacNeill EM, Englender SJ. The changing epidemiology of invasive group A streptococcal infections and the emergence of streptococcal toxic shock-like syndrome. A retrospective population-based study. JAMA. 1993;269:384-9. http://dx.doi.org/10.1001/ jama.1993.03500030082037

4. Factor SH, Levine OS, Schwartz B, Harrison LH, Farley MM, McGeer A, et al. Invasive group A streptococcal disease: risk factors for adults. Emerg Infect Dis. 2003;9:970-7. http://dx.doi. org/10.3201/eid0908.020745

5. Centers for Disease Control and Prevention. Prevention of invasive group A streptococcal disease among household contacts of case patients and among postpartum and postsurgical patients: recommendations from the Centers for Disease Control and Prevention. Clin Infect Dis. 2002;35:950-9. http://dx.doi.org/10.1086/342692

6. Barnham M, Weightman N, Chapman S, Efstratiou A, George RC Stanley J. Two clusters of invasive Streptococcus pyogenes infection in England. Adv Exp Med Biol. 1997;418:67-9. http://dx.doi. org/10.1007/978-1-4899-1825-3_17

7. Cartwright K, Logan M, McNulty C, Harrison S, George R, Efstratiou A, et al. A cluster of cases of streptococcal necrotizing fasciitis in Gloucestershire. Epidemiol Infect. 1995;115:387-97. http://dx.doi.org/10.1017/S0950268800058544

8. El-Bouri KW, Lewis AM, Okeahialam CA, Wright D, Tanna A, Joynson DH. A community outbreak of invasive and non-invasive group A beta-haemolytic streptococcal disease in a town in South Wales. Epidemiol Infect. 1998;121:515-21. http://dx.doi. org/10.1017/S095026889800168X

Address for correspondence: Aaron M. Harris, Centers for Disease Control and Prevention, 1600 Clifton Rd NE, Mailstop G37, Atlanta, GA 30329-4027, USA; email: ieo9@cdc.gov

\section{Multidrug-Resistant Tuberculosis Outbreak in Gaming Centers, Singapore, 2012}

\author{
Cynthia B.E. Chee, Suay-Hong Gan, \\ Rick T. Ong, Li-Hwei Sng, Christopher W. Wong, \\ Jeffery Cutter, Min Gong, Hui-Maan Seah, \\ Li Yang Hsu, Suhana Solhan, Peng-Lim Ooi, \\ Eryu Xia, Jayne T. Lim, Chwee-Kim Koh, \\ Soon-Kok Lim, Han-Kee Lim, and Yee-Tang Wang
}

Author affiliations: Tan Tock Seng Hospital, Singapore (C.B.E. Chee, S.-H. Gan, L.Y. Hsu, C.-K. Koh, H.-K. Lim, Y.-T. Wang); Saw Swee Hock School of Public Health, Singapore (R.T. Ong, L.Y. Hsu); Singapore General Hospital, Singapore (L.-H. Sng); Genome Institute of Singapore, Singapore (C.W. Wong, M. Gong, H.-M. Seah); Ministry of Health, Singapore (J. Cutter, S. Solhan, P.-L. Ooi, J.T. Lim; Yong Loo Lin School of Medicine, Singapore (L.Y. Hsu); and NUS Graduate School for Integrative Science and Engineering, Singapore (E. Xia)

\section{DOI: http://dx.doi.org/10.3201/eid2101.141159}

To the Editor: Local area network (LAN) gaming centers (variant of cyber cafes) have proliferated over the past 2 decades. Patrons sometimes spend considerable time playing multiplayer computer games at these centers. We report a 2012 outbreak of multidrug-resistant tuberculosis (MDR TB) in Singapore, in which transmission occurred among 5 immunocompetent 19- to 28-year-old men within 2 LAN gaming centers. This report highlights LAN gaming centers as potential hotspots for TB transmission and notes challenges faced when conducting contact-tracing investigations in such settings.

The outbreak timeline is shown in the online Technical Appendix Figure (http://wwwnc.cdc.gov/EID/ article/21/1/14-1159-Techapp1.pdf). Patients A-D had frequented LAN center 1, but 3 months before patient A received a TB diagnosis, the center closed, and they continued their gaming activities at LAN center 2. Patient $\mathrm{E}$ had only patronized LAN center 2. In February 2012, the initial case-patient, patient A, sought medical care for a cough of 4 months' duration. Chest radiographs showed bilateral cavitary lesions, a sputum smear was positive for acid-fast bacilli, and a sputum culture grew M. tuberculosis with phenotypic resistance to rifampin, isoniazid, streptomycin, and ethionamide. Contact tracing for patient A was delayed because he defaulted on directly observed therapy after 5 days and eluded contact for 6 weeks.

Before his diagnosis, patient $A$ had spent several hours daily at LAN center 1, where he participated in gaming and worked part time. Thirty contacts from center 1 were identified, but most failed to show up for screening until Ministry 